\title{
Pre-hurricane linkages between poverty, families, and migration among Puerto Rican-origin children living in Puerto Rico and the United States
}

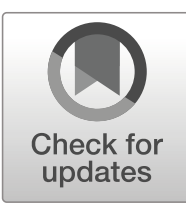

\author{
Yerís H. Mayol-García ${ }^{1}$
}

Published online: 7 August 2020

(C) This is a U.S. government work and not under copyright protection in the U.S.; foreign copyright protection may apply 2020

\begin{abstract}
Puerto Rican children comprise a historically vulnerable group that has garnered little attention from academics and policy makers. Then, Hurricanes Irma and Maria devastated the already impoverished island of Puerto Rico in 2017. It is imperative to understand the demographic, social, and economic patterns of Puerto Ricans in the past decade, in order to assess the true impact of the destructive 2017 hurricanes on Puerto Rican children and their families, and identify ways to address current population needs. This study fills this gap in the literature by providing recent pre-hurricane socioeconomic outcomes of Puerto Rican-origin children in Puerto Rico and the United States. It applies an origin-destination framework by relying on American Community Survey and Puerto Rico Community Survey data from 2012 to 2016. The analyses consider the linkages among family migration experiences, children's living arrangements, and household poverty levels. The findings are evaluated regarding prior research.
\end{abstract}

Keywords Children $\cdot$ Puerto Rico $\cdot$ Puerto Rican $\cdot$ Poverty $\cdot$ Migration $\cdot$ Family

\section{Why do recent pre-2017 Puerto Rican child poverty, family, and migration dynamics matter?}

Living in poverty as a child can greatly restrict the resources available to children while growing up. Puerto Rican-origin children residing in Puerto Rico (P.R.) and in the United States live in poverty at higher rates than other groups. For example, in 2015, $58 \%$ of Puerto Rican-origin children in Puerto Rico lived below the poverty threshold, and Puerto Rican-origin children in the United States had a poverty rate of $32 \%$, while the U.S. national child poverty rate was 20\% (Mayol-García and Burd 2018; Semega,

Yerís H. Mayol-García

yeris.h.mayol.garcia@ census.gov

1 U.S. Census Bureau, 4600 Silver Hill Road, Washington, D.C. 20233, USA 
Fontenot and Kollar 2017). Yet, only looking at poverty rates is a small part of the picture because family arrangements and migration patterns may shape these. And Puerto Ricans have historically led quite active migratory lives between the island of P.R. and the United States.

Research shows that Puerto Rican migration, either from P.R. to the United States or from the United States to P.R. is driven by the search for better socioeconomic outcomes (Duany 2002; Oropesa and Landale 2000). One study that relied on 1990 Census data points out that Puerto Rican migrants to the U.S. mainland show lower child poverty rates, in fact corroborating that migration may benefit these families (Oropesa and Landale 2000). In contrast, return migration to the island was associated with higher poverty rates for children. This is the only study to date that has applied an origindestination approach to study the intersection of family, migration, and poverty among Puerto Rican children.

However, since 1990, drastic changes in the distribution and size of the Puerto Rican population have occurred, particularly after the economic crisis of the late $2000 \mathrm{~s}$. The population on the island declined 6.8\% between 2010 and 2015, while the Puerto Rican population in the United States increased and currently accounts for more than half of all people who self-identify as having a Puerto Rican origin (Manuel Krogstad 2016; Montalvo and Laughlin 2017). As a result, Puerto Rico's total child population decreased $27.2 \%$ between 2006 and 2015 to 723 thousand children and increased in the United States by $27.7 \%$ to 1.7 million (Mayol-García and Burd 2018). These changes may be the result of differential migration and fertility patterns among Puerto Ricans in the United States and P.R. in one hand, and in the other hand, a consequence of the ongoing economic recession, which started in P.R. in 2006 and from which the island still has not fully recovered (Mora, Davila and Rodriguez 2018). In fact, P.R.'s financial outlook is so dire that since 2016, a U.S. Congress-created Fiscal Control Board (FCB) has been in charge of figuring out how to restore economic stability, including via the implementation of severe austerity measures (FCB 2019). These changes have spillover effects into children's lives that beg the following question: are the patterns found in Oropesa and Landale's study (2000) still applicable in the 2010s to describe the connections between Puerto Rican migration and children's poverty levels?

Most recently, Hurricanes Irma and Maria devastated the already impoverished island of P.R. in 2017. This disaster and its aftermath resulted in the death of almost 3000 people, the emigration of thousands, and the loss of critical infrastructure (The George Washington University 2018). This event changed the trajectories of children and their families in countless ways. To assess the impact of this disaster, first, a detailed knowledge on trends just before the hurricanes is required and is currently lacking in the literature on Puerto Rican children.

Therefore, this study asks: how is recent pre-2017 child poverty status related to Puerto Rican-origin children's family migration experiences and living arrangements? By answering this question, this research is one of the first to develop a recent analysis of the socioeconomic conditions facing Puerto Rican-origin children in Puerto Rico and the United States. This may in turn become a baseline for post-hurricane impact assessments. Inspired by the work of Oropesa and Landale (2000), this paper applies an origin-destination framework to study migration dynamics via the use of nationally representative survey data from both P.R., the origin, and the United States, the 
destination. This study also demonstrates that the survey data used (American Community Survey-ACS-and Puerto Rico Community Survey-PRCS-) may be applied for evaluating pre- and post-hurricane conditions when data from later years becomes available.

\section{Poverty and children}

Experiencing poverty in childhood is linked to negative life-long outcomes. Research shows that living in poverty is linked to child emotional and behavioral problems, lower educational outcomes, and worse health (Guo and Mullan Harris 2000; Haskins and Sawhill 2007; McLeod and Nonnemaker 2000). Families living at or below poverty rates may also experience high levels of instability, like changes in residence, household members, and participation in aid programs which have been linked to negative child outcomes. Large efforts have been made to lower poverty rates, particularly for children and their families (Haskins and Sawhill 2007).

Yet, children continue to experience poverty at higher levels than all other age groups (Semega, Fontenot and Kollar 2017; Mayol-Garcia and O'Hare 2019). The U.S. poverty rate in 2016 was $11 \%$ among adults ages 18 to $64,9 \%$ for older adults ages 65 and over, and $18 \%$ among children under the age of 18. Particularly, young children are more likely to live in poor households than teenagers (Amato 2005). Many children live with parents who are single, female, young, low-skilled, or belong to racial and ethnic minorities, all of which are associated with high levels of disadvantage (McLanahan 2004; McLeod and Nonnemaker 2000).

Puerto Rican children embody the myriad layers of disadvantage minority children face. First, there is a gap in the literature on the socioeconomic outcomes of Puerto Rican children. Puerto Ricans living on the island are excluded on one hand, from studies and reports on poverty, children, and their families in the United States because the island is a U.S. territory, where many population surveys used to develop this research are not fielded as they are across states; and in the other hand, from research on immigrant families because they are U.S. citizens. ${ }^{1}$

Second, Puerto Ricans have historically struggled more to succeed than other racial and ethnic groups on various socioeconomic indicators, like poverty. For example, in 2008, 24\% of people of Puerto Ricans in the United States lived in poverty compared with $23 \%$ of Mexicans, $14 \%$ of Cubans, $17 \%$ of other Latinos, and $9 \%$ of non-Hispanic Whites (Collazo, Ryan and Bauman 2010). On the island, the poverty level among Hispanic residents was very high, reaching 44\% in 2009 (Hugo Lopez and Velasco 2011).

Third, as children, Puerto Rican-origin children replicate the general findings of the distribution of poverty across ages with extremely high child poverty rates reaching $66.3 \%$ in Puerto Rico, and $41.5 \%$ among children of Puerto Rican migrants in the United States (Oropesa and Landale 2000). Thus, the literature on Puerto Rican child

\footnotetext{
${ }^{1}$ For example, the U.S. Census Bureau relies on data from the Current Population Survey to derive official national level poverty estimates and national annual family estimates. Additionally, there are many surveys regularly used by researchers and policy makers to study children, families, and poverty, like the Survey of Income and Program Participation, the National Longitudinal Surveys, and the National Survey of Family Growth. These surveys are not conducted in Puerto Rico or any other U.S. territories.
} 
well-being, a group belonging to a historically disenfranchised ethnic group, is quite limited despite the overwhelming evidence of the obstacles their families face.

The destruction Hurricanes Irma and Maria left behind in 2017 has exacerbated this chronic issue and other associated problems. Families in Puerto Rico and in the United States are still recovering from the loss of homes, jobs, and people, and the costs of migration and providing aid, while many youth are experiencing PTSD symptoms (Fox 2018; Orengo-Aguayo, Stewart, de Arellano et al. 2019; The George Washington University 2018; Santos-Lozada 2017). Children's poverty levels are an important indicator of well-being and access to resources, which may be shaped by historical processes, natural disasters, and migration.

\section{Families, living arrangements, and migration}

Extensive family literature underscores the importance of living arrangements as indicators of potential resources children may have access to while growing up. These include housing, food, care, emotional support, and opportunities for social and cognitive development, among many others. Numerous studies show that children's family arrangements in which a parent is absent are linked to negative child outcomes when compared with children living with two parents (Amato 2005; Landale, Thomas and Van Hook 2011; McLanahan 2004; Turney and Goodsell 2018). Parents may be absent for several reasons including divorce, nonmarital childbearing, death, migration, incarceration, or deportation. Many of these family arrangements co-occur with other sources of disadvantage. For example, single parents are more likely than married parents to have low education, low income, be younger, and be part of an ethnic/racial minority. Puerto Rican children are more likely to have single or cohabiting mothers when compared with children of other racial groups or Hispanic origins (Landale and Hauan 1996). In contrast, grandparents may offer families additional financial, emotional, and child-care resources (Bengtson 2001).

Migration can be considered a turning point in people's lives and next generations because it alters their social dynamics, resources, and opportunities (Clark, Glick and Bures 2009; Glick 2010). The extensive literature on children of immigrants and immigrant families notes that children may experience varying levels of academic success, health disadvantages, and social and emotional well-being. These may be shaped, on one hand, by the human capital that their families possess, and in the other hand, by the structural and socioeconomic barriers that specific groups may experience because of their color, race, or national origin. Immigrant families may also experience higher instability in their household memberships.

Puerto Rican children are part of a transnational community that extends across national and cultural boundaries, despite these not being international borders (Duany 2002). As such, Puerto Rican families also face many of the obstacles that immigrant families from other countries live through, like discrimination (Aranda and Rivera 2016). The one study that combined family, migration, and poverty among Puerto Ricans showed that living arrangements were an important factor in determining poverty levels among Puerto Rican children in migrant and non-migrant families (Oropesa and Landale 2000). Understanding family dynamics and arrangements is essential for addressing child and family needs, yet there is a large gap in our 
knowledge about Puerto Rican families in the past decade during which substantial population, social, and economic changes have been occurring.

\section{Puerto Rican migration}

Puerto Ricans are U.S. citizens by birth since 1917 and have been migrating back and forth between the island and the United States for over a century since Puerto Rico became a U.S. territory in 1898 (Duany 2002). Although Puerto Rican migration is officially considered internal U.S. migration because of the ability to move to the U.S. without legal restrictions, in fact, the experiences of Puerto Rican migrants are similar to those of international migrants who cross national and cultural borders. Upon arrival, Puerto Ricans must learn to communicate in English and navigate a foreign culture pervaded by racial, ethnic, and class divisions. Recent arrivals may live under particularly unstable conditions as they begin to adapt to a new culture and recover from the costs of migration (Brown, Bean and Nasir 2019). Many Puerto Ricans are drawn to the United States for better work opportunities and wage differentials to improve their socioeconomic outcomes. Although there is no consensus on whether selection on average influences who migrates from P.R. to the United States, some selection was noted for children's householders regarding education and age (Oropesa and Landale 2000).

Yet, return migration to the island is also quite common (Duany 2002, 2011). Return migration of Puerto Rican-origin people to P.R. may include people born in P.R. who became migrants or U.S.-born descendants of Puerto Rican migrants. Return migrants could do better than their non-migrant counterparts with high levels of preparedness (Cassarino 2004). However, the literature suggests that return migrants to Puerto Rico fare worse than non-migrant native-born Puerto Ricans on the island (Duany 2004; Oropesa and Landale 2000). Returned Puerto Ricans display low work skills, work more in blue collar jobs, earn lower salaries, and suffer from high levels of unemployment, despite having higher education levels (Aranda 2007; Duany 1999). These migrants may have returned for a variety of reasons, including economic and emotional difficulties in the United States (Aranda 2007). After returning, they might also suffer discrimination for having left in the first place or not speaking Spanish as a native (Duany 2011). Puerto Ricans also travel back and forth often and maintain close kinship ties between the United States and P.R., engaging in transnationalist practices (Duany 2002).

To summarize, Puerto Rican children show high levels of poverty in the United States and P.R. In order to understand the experiences of these children, migration between both places needs to be taken into consideration. For many reasons, applying immigrant theories and immigrant families' framework to Puerto Rican migration provides valuable insight.

\section{Research questions and hypotheses}

The main goal of this study is to offer an informed recent picture of the demographic, social, and economic outcomes of Puerto Rican children and their families pre- 
Hurricane Maria. It is crucial to identify population and social trends before a major disaster in order to later accurately assess its effects and develop policies to address post-disaster population needs. Specifically, this paper focuses on one main research question: Before the 2017 hurricanes, how was poverty status related to Puerto Ricanorigin children's family migration experiences and living arrangements, both in Puerto Rico and the United States?

The specific hypotheses tested are:

H1: Economic betterment: Puerto Rican-origin children in the United States have lower odds of living in poverty than Puerto Rican-origin children in nonmigrant families in Puerto Rico.

H2: Struggling return migration: Puerto Rican-origin children in return migrant families in Puerto Rico have higher odds of living in poverty compared with Puerto Rican-origin children in non-migrant families in Puerto Rico.

Additional analyses will explore the linkages between duration of migration, living arrangements, and child household poverty levels.

\section{Data and methods}

This study benefits from using binational survey data from the American Community Survey (ACS) collected in the United States and the lesser known and utilized Puerto Rico Community Survey (PRCS) collected in P.R. The ACS and PRCS provide nationally representative demographic, social, economic, and housing information on their resident populations (U.S. Census Bureau 2019). These statistics can be calculated at several geographic levels including the following: nation, state, and county or county-equivalent, like municipios in P.R. These data also include information on place of birth, current place of residence, and residence 1 year ago, which can be used to study different migrant groups. An additional migration-related question on year of entry to the United States is asked only of foreign-born people; however, Puerto Ricans are not in universe for this question because they are U.S. citizens. The PRCS is the only survey of this kind fielded in P.R. It is practically the same as the ACS providing this research the opportunity to apply an origin-destination framework, where P.R. can be considered the origin and the United States, the destination.

These surveys provide current population information because they are fielded annually since 2005 , compared with earlier data which were collected once a decade during the Decennial Census long-form (U.S. Census Bureau 2019). The Census Bureau releases 1-year files for geographic areas with populations larger than 65,000 people and 5-year files for smaller geographies and groups. So, this research also benefits from the ability to select years of data right before the hurricane.

This study uses ACS and PRCS 5-year estimates for years 2012-2016 because these files offer a large enough sample size for the migration groups and a good current snapshot of population trends pre-hurricane Maria. Although more recent posthurricane data are available for years 2017 and 2018, they are not used in the current research for three reasons. First, this paper was completed before those years of data were released to the public. Second, these years of data may need quality tests: 2017 
data collection stopped after September 2017 and 2018 data on Puerto Ricans will reflect a population in major flux given the delayed post-hurricane recovery efforts (U.S. Census Bureau 2018). ${ }^{2}$ Third, this research fills a very specific literature gap on what happened before the hurricanes; the focus is not on post-hurricane effects which corresponds to a different research question.

The main focus of this paper is children who are Puerto Rican, as determined by responses to the detailed survey question asking whether respondents are of Hispanic or Latino ethnicity. They may be of any race. Puerto Rican-origin children are analyzed as one pooled sample including U.S. and P.R. resident children in order to utilize children in Puerto Rico with no family migration as the reference group for all other migration categories. This methodology permits an evaluation of the roles of migration and living arrangements on child poverty while considering other characteristics simultaneously. The study population is limited to Puerto Rican-origin children of the householder ages 1-17 with P.R and U.S. family migration experiences exclusively, which will be explained further in the "Variables" (see living arrangements and family migration experience variables) and "Discussion" sections. For a list of the groups excluded from the sample, see Appendix Table 5. The final sample includes 105,000 unweighted children (1.8 million weighted).

Selection is a problem that all migration research faces when relying on crosssectional data, and this study is no different. Migrants may have characteristics that distinguish them from non-migrants in the origin and facilitate their departure, but ACS and PRCS data provide information on respondents' circumstances at the moment of interview, not at the time of migration. However, these surveys do offer annual information on residence 1 year ago which can be used to provide circumstantial insight into migrant selectivity, similar to Oropesa and Landale (2000) who used information on residence 5 years ago.

\section{Analysis plan}

Descriptive frequencies and multivariate logistic regressions are shown to describe the experience of poverty jointly with family migration and living arrangements of Puerto Rican-origin children. First, Puerto Rican-origin child poverty rates are shown across years 2012-2016, followed by a bivariate analysis of poverty by children's family migration experiences. Householder characteristics by specific family migration experiences, P.R. non-migrants and U.S. recent migrants, are also shown to address migrant selectivity.

Logistic regressions permit the estimation of the predicted probability of living in poverty among children as a function of several child, householder, and household covariates. In order to disentangle the linkages between poverty, migration, and living arrangements, several nested logistic regression models were run to show the extent to which control variables account for differences in poverty between children with and without family migration experience.

\footnotetext{
${ }^{2}$ PRCS data for years 2017 and 2018 have been published by the U.S. Census Bureau with adjustments to replicate weights and standard errors.
} 
The analysis relies on proc surveylogistic statements and replicate weights with the jackknife method option to develop the logistic regression models in SAS. ${ }^{3}$ Negative replicate weights were set to zero. Characteristics in the regression models are coded as dummy variables. Internal U.S. Census Bureau ACS and PRCS data were used.

\section{Variables}

Below is a brief description of the main variables analyzed with descriptive statistics shown in Table 1. The key dependent variable is household poverty status, which identifies whether children live in households with income in the past 12 months below the poverty threshold. Poverty status is calculated the same way in P.R. and the United States by comparing the family income with a set of thresholds which vary by family size and composition. ${ }^{4}$ The poverty rate for Puerto Rican-origin children in 2012-2016 is $41 \%$.

Children's living arrangements include three categories: children living with two married parents, children living with a cohabiting parent, or children living with one parent, no spouse or partner present. The parent's cohabiting partner may or may not be the child's second parent; for simplification purposes, we label this group of children as living with two cohabiting parents. Some children living with their mother only or father only may be living with a parent married to an absent spouse who is stationed overseas with the armed forces, or is incarcerated, for example. In all cases, the child must have at least one parent present who is the householder. Less than half of the sample live with married parents (47\%), compared with $14 \%$ living with cohabiting parents and $39 \%$ living with one parent.

Children are identified as living with grandparents if there is a parent or parent-inlaw of the householder present. The measure of grandparents overlaps with the living arrangements measures of parents described above. So, for example, a child living with a grandparent may be living with married parents, cohabiting parents, or only a single parent. About $4 \%$ of children live with a grandparent in the household.

The migration measures in this paper combine information on place of birth (POB), residence 1 year ago (ROYA), and current place of residence (NOW) of the householder and child of the householder to develop family migration experience dummy variables. The migration analysis is restricted to children of the householder in order to capture migration information of at least one parent who is considered a reference person and their child. Since the migration of other household members can also have significant effects on children, the selection of only householder and child migration experiences for this study could be considered as providing conservative migration estimates. Children who do not have a parent present or who have a parent who is not a designated householder are excluded from the analyses. Zero-year-old children are also

\footnotetext{
${ }^{3}$ ACS and PRCS data include 80 replicate weights to derive standard error estimates that account for the complex sample design. The ACS and PRCS use a successive difference methodology to calculate standard errors, which is similar, but different, from the jackknife method. For more information on variance estimation, see https://www2.census.gov/programs-surveys/acs/methodology/design_and_methodology/acs_design_ methodology_ch12_2014.pdf

${ }^{4}$ The poverty measure adjustments that Oropesa and Landale (2000) implemented in their study are not necessary here because "consensually married" is no longer an option in the marital status question.
} 
Table 1 Descriptive statistics of Puerto Rican-origin children of the householder 1-17 years old

\begin{tabular}{llr}
\hline Characteristics & All PR-origin children & SE \\
\hline Total weighted (in thousands) & 1848 & 7.40 \\
Child characteristics & & \\
Age (mean) & 9.2 & 0.02 \\
Male & 51.3 & 0.13 \\
Female & 48.7 & 0.13
\end{tabular}

Family characteristics

Family migration experience

P.R. migrants

U.S. no migration

U.S. migrants

Living arrangements

2 married parents

2 Cohabiting parents

One parent, no spouse or partner

Grandparent presence

No grandparent present

Grandparent present

Householder characteristics

Work status (by the number of hours worked last week)

No hours worked

Part-time (less than $35 \mathrm{~h}$ )

Full-time ( $35 \mathrm{~h}$ or more)

Householder educational attainment

High school or less

Some college

Bachelor's degree or higher

Ability to speak English

Not well or not at all

Very well/well or only speaks English

Household characteristics

Number of children

One child

Two children

Three or more children

Poverty status

Not in poverty

Percentages may not add to 100 due to rounding

Source: U.S. Census Bureau, ACS 2012-2016 5-year estimates and PRCS 2012-2016 5-year estimates $S E$ standard error 
excluded because they do not have values for their ROYA (see Appendix Table 5 for more information on sample selection criteria).

Two versions of the migration categories were developed: a detailed version with six categories (used in the descriptive statistics section) and a collapsed version with four categories (used in the regression models). Table 2 shows how each migration measure is developed based on the 3 pieces of information available for children and their householder: POB, ROYA, and NOW. The top three categories are children interviewed in P.R. (NOW=P.R.). Children in "P.R. no migration" family experiences live in families where the child and the householder were both born in Puerto Rico (POB=P.R.), lived in Puerto Rico 1 year ago (ROYA=P.R.), and lived in P.R. at the moment of the survey (NOW=P.R.). Because this is a family level variable, if either the child or the householder was determined to have migration experience, then the child was categorized in the corresponding migration category. For example, if a child was born in P.R., ROYA = P.R., and was interviewed in P.R. (NOW=P.R.), but the householder either had $\mathrm{POB}=\mathrm{U} . \mathrm{S}$., or ROYA = U.S., then the child was categorized as in a P.R. migrant family.

For the regression analyses, the recent migration variables were collapsed with the long-term migration variables (migrated more than 1 year ago) into the "P.R. migrants" and "U.S. migrants" categories due to small sample size. Children with householder or own migration experience, like place of birth and residence 1 year ago, that is abroad (not Puerto Rico or the United States) are excluded from the regression analysis. This allows the analytical focus to be on Puerto Rico-US migration dynamics. The limitations in the "Discussion" section details the migration data and measure constraints of this study. About $29 \%$ are children in P.R. non-migrant families, $3 \%$ are in P.R. migrant families, $48 \%$ are in U.S. non-migrant families, and $20 \%$ are in U.S. migrant families (see Table 1).

Other variables included in the analysis are dichotomous householder characteristics: completing high school or less (41\%), having some college (36\%), having a bachelor's degree or more (22\%), no hours worked in the past week $(27 \%)$, worked part-time (less than $35 \mathrm{~h}, 16 \%$ ), worked full-time ( $35 \mathrm{~h}$ or more, $57 \%$ ), ability to speak English very well/well or only speak English (76\%) or speak English not well/not at all $(24 \%))^{5,6}$ Two child characteristics are included: sex (51\% male and $49 \%$ female) and age as a continuous variable going from 1 to 17 (mean of 9.2 years). Additional measures of the number of children of the householder distinguish between households with one child (30\%), two children $(41 \%)$, and three or more children (29\%). These characteristics are included to account for possible selection across migration groups, clustering, and demographic differences among children.

\section{Results}

How is poverty distributed across analysis years? For context purposes, Fig. 1 shows the average poverty rate of Puerto Rican-origin children across years 2012-2016 in

\footnotetext{
${ }^{5}$ The ACS/PRCS first asks respondents if they only speak English; when respondents say "No," then a follow-up 4-category question asks about their ability to speak English.

${ }^{6}$ Householder information may include minor inconsistencies when a person who owns or rents the interviewed residence is not present; in these instances, any adult over the age of 15 years may serve as the householder.
} 
Table 2 Information used to create Puerto Rico-US family migration experience categories

\begin{tabular}{|c|c|c|c|c|}
\hline \multicolumn{3}{|c|}{ Child and householder migration experience information } & \multicolumn{2}{|c|}{ Family migration experience categories } \\
\hline $\begin{array}{l}\text { Place of } \\
\text { birth (POB) }\end{array}$ & $\begin{array}{l}\text { Residence one year } \\
\text { ago (ROYA) }\end{array}$ & $\begin{array}{l}\text { Current place of } \\
\text { residence (NOW) }\end{array}$ & $\begin{array}{l}\text { Detailed (used in } \\
\text { descriptive analysis) }\end{array}$ & $\begin{array}{l}\text { Collapsed (Used in } \\
\text { regression models) }\end{array}$ \\
\hline P.R. & P.R. & P.R. & P.R. no migration & P.R. no migration \\
\hline U.S. & P.R. & P.R. & $\begin{array}{l}\text { P.R. long-term mi- } \\
\text { grants }\end{array}$ & P.R. migrants \\
\hline P.R. or U.S. & U.S. & P.R. & P.R. recent migrants & P.R. migrants \\
\hline U.S. & U.S. & U.S. & U.S. no migration & U.S. no migration \\
\hline P.R. & U.S. & U.S. & $\begin{array}{l}\text { U.S. long-term mi- } \\
\text { grants }\end{array}$ & U.S. migrants \\
\hline P.R. or U.S. & P.R. & U.S. & U.S. recent migrants & U.S. migrants \\
\hline
\end{tabular}

Source: U.S. Census Bureau, ACS 2012-2016 5-year estimates and PRCS 2012-2016 5-year estimates

P.R. and the United States. The child poverty rate has steadily declined in the United States from a high of $35 \%$ in 2012 to a low of $29 \%$ in 2016 . The poverty rate of children in P.R. has fluctuated between 56 and $59 \%$ and has not differed statistically across analysis years.

How is poverty distributed across detailed family migration experiences? Although high, the poverty rate for all Puerto Rican-origin children (41\%) masks significant differences across migration groups. Figure 2 shows the percent distribution and poverty rates of Puerto Rican-origin children by detailed family migration experience during the period of 2012-2016. The distribution of the child population across family migration experiences does not match how children in each migration category experience poverty.

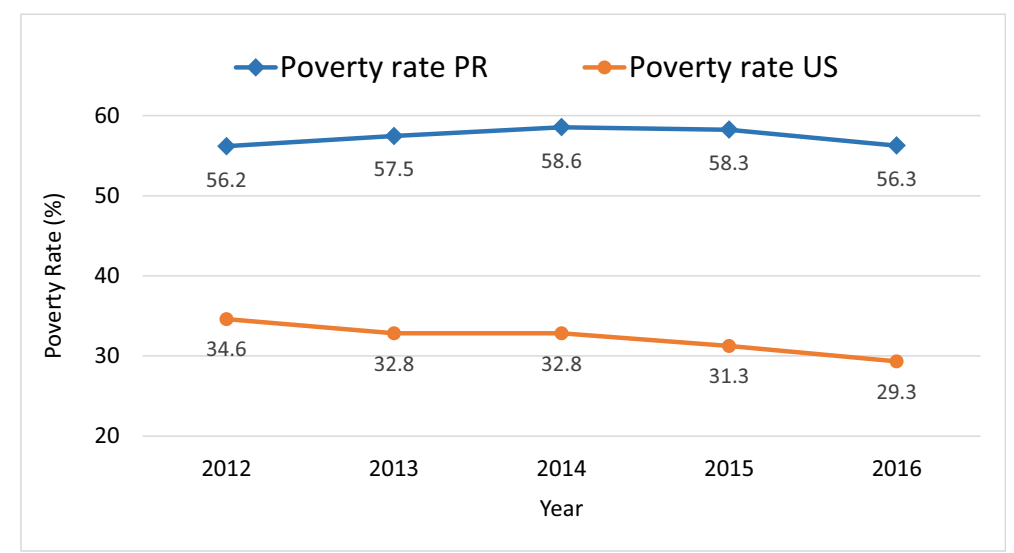

Fig. 1 Poverty rates among Puerto Rican-origin children by year and place of residence. Source: U.S. Census Bureau, ACS 2012-2016 1-year estimates, PRCS 2012-2016 1-year estimates. Universe: Puerto Rican-origin children ages $0-17$ years old living in households 


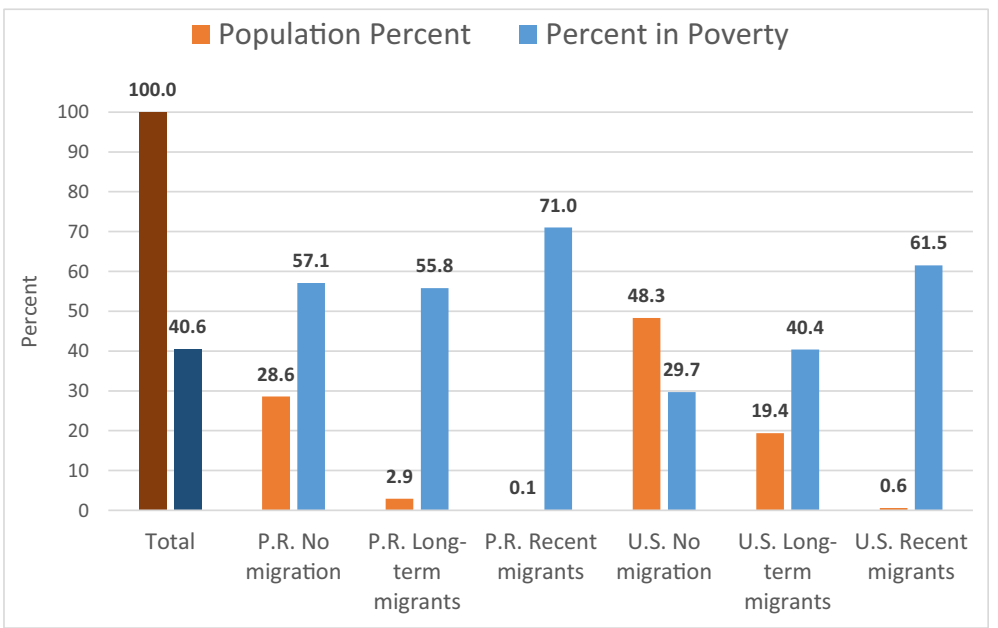

Fig. 2 Percent of Puerto Rican-origin children and percent in poverty by detailed family migration experience, ACS/PRCS 2012-2016. Source: U.S. Census Bureau, ACS 2012-2016 5-year estimates and PRCS 20122016 5-year estimates

Despite children in P.R. non-migrant families comprising only $29 \%$ of all children, they have a poverty rate of $57 \%$, which is almost double the poverty rate of children in U.S. non-migrant families (30\%) who make up $48 \%$ of all children. Children in U.S. long-term migrant families are the third largest group of children (19\%) and $40 \%$ live in poverty. Thus, migration and residence in the United States may be associated with lower poverty rates than the reference group (children in P.R. non-migrant families), supporting H1.

Although comprising a very small proportion of all children (less than 1\%), the highest poverty rates correspond to children with recent family migration experience to Puerto Rico $(71 \%)$ or the United States $(62 \%){ }^{7}$ These families may still be recovering from the costs of migration since they arrived to their current residence less than 1 year ago.

In comparison with children in P.R. recent migrant families, children in P.R. longterm migrant families have a poverty rate of $56 \%$, but this is not statistically different from children in P.R. non-migrant families (57\%). This result counters H2, but could also support the literature on duration of migration. Return migrants to Puerto Rico may experience high levels of disadvantage, in addition to, recovering from the costs of migration, as evidenced by the high poverty rates of children in P.R. recent migrant families. Yet, these disadvantages seem to disappear with a longer residence in P.R. to the point where return migrants' poverty levels are the same as non-migrants in P.R, as experienced by P.R. long-term migrant families. In other words, return migration to Puerto Rico may result in worse socioeconomic outcomes for children that level out with time. Importantly, all six of these poverty rates are much higher than the U.S. child poverty rate in 2016 of $18 \%$, indicating that regardless of migration, Puerto Rican-

\footnotetext{
${ }^{7}$ The poverty rates of children in P.R. recent migrant families (71\%) and U.S. recent migrant families $(62 \%)$ are not statistically different to each other.
} 
origin children and their families continue to have limited access to resources (Semega, Fontenot and Kollar 2017).

To summarize, the descriptive statistics suggest migration to the United States may be linked to lower poverty rates than in Puerto Rico. Migration, particularly recent migration occurring in the past year, may be linked to the highest poverty rates. Return migrants to Puerto Rico fare badly upon arrival, but with enough time seem to end up with similar socioeconomic outcomes as non-migrants. Notably, Puerto Rican-origin children have high poverty rates. While the descriptive statistics are consistent with the hypotheses, the logistic regressions are able to control for variables also associated with poverty and with migrant selectivity.

Is there migrant selectivity? Table 3 shows select householder and household characteristics in P.R. non-migrant families and U.S. recent migrant families to offer proxy information on migrant selection. These groups differed statistically in few characteristics. U.S. recent migrant householders were younger and spoke English better than P.R. nonmigrant householders. Regarding household composition, U.S. recent migrant householders had marginally significant higher proportions of being a single parent, living with a parent, or parent-in-law (grandparent to the child) and living with three or more children.

How is poverty associated with collapsed family migration experiences and children's living arrangements? Four logistic regression models were run to predict the odds of a Puerto Rican child living in a poor household (see Table 4). Model 1 includes only family migration experience, model 2 adds living arrangements and presence of grandparents, model 3 adds householder and child characteristics, and model 4 includes family migration experience and living arrangements interaction terms. Model 4 is used to show predicted probabilities of poverty later on. Since results were robust when using only one child per household selected randomly to account for clustering, the models shown include all children in the original sample. ${ }^{8}$ Results were also robust to different householder employment measures, like in/out of the labor force, unemployed/working, and logged hours worked in the past week; part-time/full-time work measures were selected for providing the best model fit.

The results for family migration experiences as predictors of household poverty show the same pattern across models. In all models, children in P.R. non-migrant families are the reference group. The odds of living in a poor household for P.R. migrants are not statistically different from the odds of living in a poor household for children in P.R. non-migrant families. This result counters H2, which holds that children may experience poverty more often in families with return migration experience, but as discussed earlier may suggest that return migrants adjust to non-migrants socioeconomic outcomes in Puerto Rico with time.

However, the odds of children living in a poor household for the other two groups, U.S. non-migrants and U.S. migrants, are significantly lower than the odds of children living in a poor P.R. non-migrant family supporting H1, which holds that migration to the United States may be associated with lower poverty levels. These odds become even smaller as we place additional variables in the models suggesting that migration to the United States retains a diminishing effect on children's poverty levels separate from

\footnotetext{
${ }^{8}$ The cluster statement cannot be combined with replicate weights in this SAS modeling technique.
} 
Table 3 Children's householder characteristics by select family migration experience

\begin{tabular}{|c|c|c|c|c|}
\hline Children's householder characteristics & PR non-migrants & $\mathrm{SE}$ & US recent migrants & SE \\
\hline \multirow[t]{2}{*}{ Total weighted (in thousands) } & 529 & 2.55 & 11 & 0.63 \\
\hline & 100.0 & & 100.0 & \\
\hline \multicolumn{5}{|l|}{ Poverty status } \\
\hline Not in poverty & 42.9 & 0.46 & 38.5 & 2.92 \\
\hline In poverty & 57.1 & 0.46 & 61.5 & 2.92 \\
\hline Age (mean) & 37.3 & 0.05 & 33.5 & $0.28 * * *$ \\
\hline \multicolumn{5}{|l|}{ Sex } \\
\hline Male & 38.2 & 0.47 & 36.5 & 3.28 \\
\hline Female & 61.8 & 0.47 & 63.5 & 3.28 \\
\hline \multicolumn{5}{|l|}{ Householder educational attainment } \\
\hline Less than high school & 12.0 & 0.31 & 16.0 & 2.53 \\
\hline High school & 28.5 & 0.41 & 29.3 & 3.05 \\
\hline Some college & 31.2 & 0.49 & 31.5 & 3.10 \\
\hline Bachelor's degree & 20.8 & 0.33 & 17.5 & 2.39 \\
\hline Graduate or professional degree & 7.4 & 0.19 & 5.8 & 1.33 \\
\hline \multicolumn{5}{|l|}{ Ability to speak English } \\
\hline Only speaks English & 2.9 & 0.12 & 1.8 & 1.00 \\
\hline Very well & 14.1 & 0.29 & 34.1 & $2.87 * * *$ \\
\hline Well & 15.6 & 0.31 & 25.9 & 2.72 \\
\hline Not well & 23.9 & 0.36 & 22.8 & $2.67 * * *$ \\
\hline Not at all & 43.5 & 0.43 & 15.4 & $2.66 * * *$ \\
\hline \multicolumn{5}{|c|}{ Work status (by the number of hours worked last week) } \\
\hline No hours worked & 37.3 & 0.42 & 32.6 & 3.24 \\
\hline Part-time (less than $35 \mathrm{~h}$ ) & 15.7 & 0.36 & 16.4 & 2.50 \\
\hline Full-time ( $35 \mathrm{~h}$ or more) & 47.1 & 0.49 & 51.0 & 3.48 \\
\hline \multicolumn{5}{|l|}{ Children's living arrangements } \\
\hline 2 married parents & 46.0 & 0.49 & 39.9 & $3.21+$ \\
\hline 2 cohabiting parents & 16.5 & 0.32 & 15.5 & 2.07 \\
\hline One parent, no spouse, or partner & 37.5 & 0.43 & 44.7 & $3.07 *$ \\
\hline \multicolumn{5}{|l|}{ Children's grandparent presence } \\
\hline No grandparent present & 97.7 & 0.12 & 94.4 & $1.64 *$ \\
\hline Grandparent present & 2.3 & 0.12 & 5.6 & $1.64 *$ \\
\hline \multicolumn{5}{|l|}{ Number of children 1} \\
\hline One child & 28.9 & 0.38 & 26.1 & 2.44 \\
\hline Two children & 46.5 & 0.44 & 42.5 & 2.78 \\
\hline Three or more children & 24.7 & 0.42 & 31.4 & $2.87 *$ \\
\hline
\end{tabular}

Statistical significance at $0.1(+), 0.05(*), 0.01(* *), 0.001(* * *)$

Percentages may not add to 100 due to rounding

Source: U.S. Census Bureau, ACS 2012-2016 5-year estimates and PRCS 2012-2016 5-year estimates $S E$ standard error

${ }^{1}$ Refers to all children in sample 
Table 4 Odds ratios of living in a poor household among 1-17-year-old Puerto Rican-origin children of the householder

Variables/Models

Model 1 Model 2 Model 3 Model 4

Dependent variable (household in poverty)

Independent variables

Family migration experience (Ref. no migration in P.R.)

$\begin{array}{llll}1.00 & 1.00 & 1.00 & 1.00 \\ 0.98 & 0.95 & 1.07 & 0.98\end{array}$

P.R. migrants

U.S. no migration

$0.32 * * * \quad 0.26 * * * \quad 0.26 * * * \quad 0.17 * * *$

U.S. migrants

$0.52 * * * \quad 0.46^{* * *} \quad 0.38^{* * *} \quad 0.36^{* * * *}$

Living arrangements (Ref. 2 married parents)

2 cohabiting parents

One parent, no spouse or partner present

Grandparent presence (Ref. no grandparents)

Grandparent present

Householder educational attainment (Ref. high school or less)

Householder has some college

Householder has a bachelor's degree or higher

Householder ability to speak English (Ref. not well or not at all)

Householder only speaks English or speaks English very well/well

Householder work status (Ref. no hours worked in the past week)

Householder works part-time (less than $35 \mathrm{~h}$ )

Householder works full-time (35 or more hours)

Number of children (Ref. one child)

Two children

Three or more children

Child age (continuous variable 1-17 years)

$1.00 \quad 1.00 \quad 1.00$

$5.79 * * * 6.43 * * * \quad 4.69 * * *$

$6.97 * * * \quad 7.25 * * * \quad 5.14 * * *$

$1.00 \quad 1.00 \quad 1.00$

$0.48 * * * 0.39 * * * \quad 0.39 * * *$

$1.00 \quad 1.00$

$0.50 * * * \quad 0.51 * * *$

$0.14 * * * 0.14 * * *$

$1.00 \quad 1.00$

$0.57 * * * \quad 0.57 * * *$

$1.00 \quad 1.00$

$0.46 * * * \quad 0.45 * * *$

$0.07 * * * 0.07 * * *$

$1.00 \quad 1.00$

$1.53 * * * \quad 1.54 * * *$

$3.24 * * * 3.29 * * *$

$0.95 * * * 0.95 * * *$

Family migration experience and living arrangements interactions

P.R. migrants $\times 2$ cohabiting parents

P.R. migrants $\times 1$ parent

1.24

U.S. no migration $\times 2$ cohabiting parents

$1.97 * * *$

U.S. no migration $\times 1$ parent

U.S. migrants $\times 2$ cohabiting parents

U.S. migrants $\times 1$ parent

Model

Unweighted sample (in thousands)

$105 \quad 105 \quad 105 \quad 105$

-2 log-likelihood (in thousands)

$2386 \quad 2058 \quad 1401 \quad 1396$

Source: U.S. Census Bureau, ACS 2012-2016 5-year estimates and PRCS 2012-2016 5-year estimates Statistical significance at $0.05(*), 0.01(* *), 0.001(* * *)$

the covariates included in the analysis. For example, in model 1, children in U.S. migrant families have an odds of being poor that is about half $(52 \%)$ the odds of children living in poor P.R. non-migrant families; by model 3, these odds for U.S. 
migrant families decrease to less than two-fifths (38\%) of the odds of being poor for the reference group. In model 3, the odds of living in a poor household for children in nonmigrant families in the United States are about one-quarter $(26 \%)$ the odds of children living in a poor non-migrant household in Puerto Rico. Children in U.S. resident families seem to be significantly less likely to live in poverty than children in P.R. non-migrant families.

Living arrangements are also associated with household poverty levels among Puerto Rican-origin children. Children living with married parents comprise the reference group. The odds of living in a poor household for children with cohabiting parents are 6.4 times higher than the odds of children living with poor married parents in model 3. Children with one parent have an odds of being poor that is 7.3 times higher than for children living with poor married parents. Children in cohabiting households seem to be more similar to children with one parent than those living with married parents, in terms of their very high odds of being poor.

In fact, after considering interaction terms (model 4) and holding most covariates constant, the differences in the predicted probabilities of a Puerto Rican-origin child living in a poor household suggest that living arrangements may magnify or minimize the link that migration has on children's poverty levels (Fig. 3). ${ }^{9}$ Across all migration categories, the lowest probabilities of being poor (5\% or less) belong to children with married parents. In contrast, children in Puerto Rico with either cohabiting parents or single parents (both P.R. non-migrant and P.R. migrant families) had a predicted probability of living in poverty between 37 and $41 \%$. In other words, among P.R. resident children, their predicted probabilities do not differ much across migration categories, countering H2. Among children with cohabiting parents, only $9 \%$ of children in U.S. non-migrant families and $18 \%$ of children in U.S. migrant families are predicted to be poor, compared with $38 \%$ of children in P.R. non-migrant families, supporting H1. In other words, among children with cohabiting parents, the probability of being poor among children in U.S migrant families is about $20 \%$ lower than for children in P.R. non-migrant families, and about $30 \%$ lower for children in U.S. nonmigrant families. The probabilities of living in a poor household among children with one parent are slightly higher across family migration experiences compared with those of children with cohabiting parents. Notably, the predicted probabilities' results support the economic betterment hypothesis (H1), do not support the struggling return migration hypothesis (H2), and point to possible similarities in the economic hardships facing children living with cohabiting parents and those living with one parent.

Regarding the other covariates included in model 3, as expected, children living with grandparents have a lower odds of being poor (61\% lower) than children who do not live with grandparents. Results for householder and child characteristics show expected trends (see model 3). Children living with householders who worked part-time or fulltime show much lower odds (54\% and $93 \%$ lower, respectively) of being poor than children living with householders who did not work at all. Similarly, children living with a householder who had some years of college or earned a bachelor's degree or higher show much lower odds (50\% and $86 \%$ lower, respectively) of being poor than

\footnotetext{
${ }^{9}$ The predicted probabilities are based on the full logistic regression model 4 with interaction terms, where a child with a mean age lives with no grandparents and no other children (there is only one child), a householder who worked full-time, did not speak English well or at all, and had a BA degree or more studies.
} 


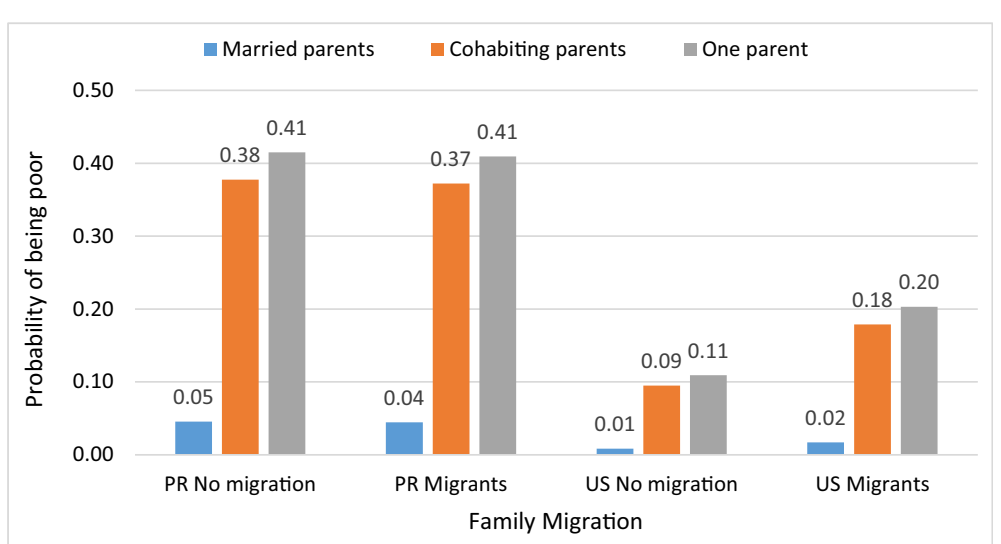

Fig. 3 Predicted probabilities of a Puerto Rican-origin child age 1-17 living in a poor household with no coresident grandparents by family migration experience and living arrangements. Source: U.S. Census Bureau, ACS 2012-2016 5-year estimates and PRCS 2012-2016 5-year estimates. Predicted probabilities based on the full logistic regression model 4, where a child of a mean age lives with no grandparents and no other children (there is only one child), a householder who worked full-time, did not speak English well or not at all, and had a BA degree or higher

the reference group. Children living with householders who speak English very/well or only speak English had an odds of being poor that was half the odds of being poor among children living with householders who do not speak English well or not at all. Children living in households with multiple children show much higher odds of being poor (1.5 times higher for two children and 3.2 times higher for three or more children) than children in poor households where there was only one child.

This section has established that migration to the United States is associated with lower household poverty levels for Puerto Rican-origin children in support of H1. Children in P.R. migrant families did not differ in the probabilities of living in a poor household compared with the reference group, countering $\mathrm{H} 2$. The evidence points to the critical role that living arrangements have on child poverty levels across migration groups, with children in single and cohabiting parent households at much higher risk of being poor, while holding other factors constant.

\section{Discussion}

This project provides a recent analysis of the pre-Hurricane Maria connections among poverty, migration, and living arrangements of Puerto Rican-origin children in the United States and in Puerto Rico. Methodologically, this research benefits from the ability to study the sending and receiving populations in tandem with nationally representative ACS and PRCS data on the U.S. and P.R populations. In fact, this research demonstrates that these data may be an excellent option for future studies assessing the impact of the 2017 hurricanes on the Puerto Rican population.

The results of this study confirm that the findings of prior research regarding Puerto Rican migration still hold true in recent years. The experience of living in a poor household between 2012 and 2016 is less common among children in 
migrant families in the United States compared with children in non-migrant families in P.R. This suggests that U.S. migration might still be associated with socioeconomic benefits for children and their families in the form of lower poverty rates, as Oropesa and Landale (2000) first noted using 1990 Census data. After controlling for covariates, children in U.S. migrant and U.S. non-migrant families have odds of being poor that are respectively about two-fifths and onequarter the odds of a child living in a poor P.R. non-migrant family. However, it should be noted that despite possible socioeconomic benefits of migration to the United States compared with living in P.R., Puerto Rican-origin children in the United States still have higher poverty rates than the U.S. national child poverty rate. Their families may be facing similar struggles as other immigrant families which constrain the resources they may offer to children.

The availability of information on residence 1 year ago in P.R. and the United States permitted distinguishing children in long-term migrant families from those in recent migrant families. As the literature notes (Brown, Bean and Nasir 2019), recent migrants may not fare well as they recover from the negative costs of migration. This study supports previous work by finding that children in families that arrived less than 1 year ago to their respective destinations (P.R. or the United States) show much higher poverty rates than families with longer durations of residence or families with no migration.

Return migrants to P.R. both confirmed and countered the proposed hypotheses. The literature on return migrants to Puerto Rico suggests that they do not fare well for many reasons (Aranda 2007; Duany 2011). The findings in this study signal that recent return migrant families (P.R. recent migrants) may fare worse than non-migrants in P.R., possibly because the negative costs of migration could still be playing a role. Yet, return migrant families that have been in P.R. for more than a year, and make up the majority of the P.R. migrant category used in the regression analysis, are not statistically different from the reference group. These two findings suggest that upon arrival, return migrants may be more likely to live in poverty, but as time progresses, their situation changes and becomes more similar to that of non-migrants in P.R.

Living arrangements are particularly important. Children living with cohabiting parents and with one parent were several times more likely to live in poor households than children living with married parents, even across migration categories (Amato 2005; McLanahan 2004).

This research is limited in several ways. Like most studies on migration using cross-sectional data, this study suffers from endogeneity bias. Although the results shown suggest that migrant selectivity might not play a large role, it cannot be fully accounted for or measured since the survey collects information on migrants after people moved, not immediately prior, during, or immediately after migrating. Migrants may have different characteristics compared with non-migrants that facilitate or motivate them to migrate, including being poor. Furthermore, although the literature on Puerto Rican migration notes the importance of transnational migration between the United States and P.R., any movement occurring between the three observed data points: place of birth, residence 1 year ago, and current place of residence cannot be assessed in this study due to data limitations (Duany 2011). Therefore, it is likely that some non-migrant families in this study have migration experience between P.R. and the United States. Additionally, the 
exact time a household experiences poverty is unknown due to data limitations; the survey notes only if it occurred during the past 12 months prior to the interview. Also, poverty status is updated annually for changes in cost of living using the consumer price index, but does not take into account regional or state differences (Bishaw and Benson 2017). For all of these reasons, causal interpretations of the connections between migration and poverty cannot be made in this study.

Due to the complicated nature of the family migration measures used to answer the research question, this study excludes children in subfamilies (who are not children of the householder), children not living with parents and children living in group quarters. These children may be particularly vulnerable due to more complex or unstable living arrangements, and would greatly benefit from future research focused on them. These groups were excluded in order to make a clearer analysis of parent/child migration experiences and poverty levels.

\section{Conclusions and post-hurricane implications}

Puerto Rican-origin children make up a vulnerable group because they experience high poverty rates, on the island and the mainland, that may deepen across family migration experiences and vary by living arrangements. By helping us understand the trends before the hurricanes, this research may serve as a baseline to evaluate the consequences of the aftermath of the storms for Puerto Rican families in both the United States and P.R.

Based on the results shown and the disastrous impact of Hurricanes Irma and Maria, the following post-hurricane trends may be expected. First, we can anticipate enumerating even higher numbers of Puerto Rican-origin children living in the United States than in P.R. due to the mass emigration flows following the hurricanes (Alexander, Polimis and Zagheni 2019; Sutter and Hernandez 2018). Second, Puerto Rican-origin children's families may look quite different, with fewer children living with two married parents. For example, many children were sent from P.R. to the United States with parents, relatives, or acquaintances, to continue their studies due to school closures and inadequate school resources on the island (Hinojosa, Roman and Melendez 2018; Holpuch and Kilani 2019). Third, children's families, especially those with cohabiting or single parents, at both locations, P.R. and the United States, may show higher poverty levels since they might still be recuperating from the hurricanes or the negative costs of their recent emigration especially relevant for U.S. recent migrant families. The fact that many houses in P.R. in 2018 still had blue tarps over their roofs points to continued financial instability (Fox 2018). Even non-migrant U.S. families may be recovering from the disaster since the diaspora also provided much needed aid in the recovery efforts (Santos-Lozada 2017).

Furthermore, Puerto Rico continues to suffer a grave economic crisis, earthquakes, and the Covid-19 pandemic. Therefore, there is still much to be done to assess the impact of the hurricanes and these other crises to identify solutions that address the needs of Puerto Rican children and their families. Fortunately, ACS and PRCS may be a good source of current data to study this population. Soon, 2019 data files will be published which will may be combined with earlier years. Other questions to address using later years of ACS/PRCS data are as follows: How have the hurricanes impacted 
Puerto Rican-origin children's poverty levels and families in P.R. and the United States? Is migration from P.R. to the United States post-Hurricane Maria still associated with lower poverty levels among Puerto Rican families? Are there geographic differences in these linkages across municipios in P.R. and states or counties in the United States? How are children living without parents faring? It is our responsibility to continue understanding, measuring, and addressing the impact that the deadly hurricane season of 2017 continues to have on Puerto Ricans and their children.

Acknowledgments This study was made possible through the support of the U.S. Census Bureau. The research greatly improved thanks to the insightful feedback from reviewers and editors of the Population and Environment journal and attendees of the 2018 and 2019 Population Association of America conferences where earlier versions of this paper were presented as SEHSD Working Paper Number 2019-14.

Compliance with ethical standards The views expressed on statistical and methodological issues are those of the author and do not necessarily represent the views of the U.S. Census Bureau. This paper meets all the U.S. Census Bureau's Disclosure Review Board (DRB) standards and has been assigned a DRB approval number CBDRB-FY20-POP001-0136.

\section{Appendix}

Table 5 Sample selection criteria

\begin{tabular}{lll}
\hline Groups & $\begin{array}{l}\text { Frequency } \\
\text { (in thousands) }\end{array}$ & $\begin{array}{l}\text { SE (in } \\
\text { thousands) }\end{array}$ \\
\hline All Puerto Rican-origin children & 2413 & 8.47 \\
In group quarters & 10 & 0.38 \\
In subfamilies & 246 & 3.21 \\
Living with no parents & 112 & 1.83 \\
0-year-old children of the householder & 92 & 1.69 \\
Abroad family migration experience of child or householder & 105 & 2.15 \\
Final sample: child of householder 1-17 years old with P.R./U.S. family migration & 1848 & 7.40 \\
$\quad$ experiences & & \\
\hline
\end{tabular}

Source: U.S. Census Bureau, ACS 2012-2016 5-year estimates and PRCS 2012-2016 5-year estimates

$S E$ standard error

\section{References}

Alexander, M., Polimis, K. \& Zagheni, E. (2019). The impact of Hurricane Maria on out-migration from Puerto Rico: evidence from Facebook data. Population Association of America annual meeting, Austin, Texas, April 11, 2019.

Amato, P. (2005). The impact of family formation change on the cognitive, social, and emotional well-being of the next generation. The Future of Children, 15(2), 75-96.

Aranda, E. M. (2007). Emotional bridges to Puerto Rico: migration, return migration, and the struggles of incorporation. U.S.A: Rowman and Littlefield Publishers.

Aranda, E., \& Rivera, F. I. (2016). Puerto Rican families in Central Florida: prejudice, discrimination, and their implications for successful intergration. Women, Gender, and Families of Color, 4(1), 57-85. 
Bengtson, V. L. (2001). Beyond the nuclear family: the increasing importance of multigenerational bonds. Journal of Marriage and the Family, 63(1), 1-16.

Bishaw, A. \& Benson, C. (2017). Poverty: 2015 and 2016. U.S. Census Bureau, American Community Survey Brief. Accessed on 8/13/2018. Available at https://www.census. gov/content/dam/Census/library/publications/2017/acs/acsbr16-01.pdf

Brown, S. K., Bean, F. D., \& Nasir, S. (2019). International migration. In D. L. Poston Jr. (Ed.), Handbook of Population (2nd ed., pp. 421-455). Berlin: Springer.

Cassarino, J. P. (2004). Theorising return migration: the conceptual approach to return migrants revisited. International Journal on Multicultural Societies, 6(2), 253-279.

Clark, R. L., Glick, J. E., \& Bures, R. M. (2009). Immigrant families over the life course: research directions and needs. Journal of Family Issues, 30(6), 852-872.

Collazo, S.G., Ryan, C.L. \& Bauman, K.J. (2010). Profile of the Puerto Rican population in United States and Puerto Rico: 2008. U.S. Census Bureau, SEHSD Working Paper presented at PAA 2010, Dallas TX. Accessed on 08/25/2017. https:/www.census.gov/content/dam/Census/library/working-papers/2010 /demo/collazo-ryan-bauman-paa2010-paper.pdf

Duany, J. (1999). La población y la migración en Puerto Rico de cara al siglo XXI”. In F. Martinez (Ed.), Futuro Económico de Puerto Rico. San Juan, PR.

Duany, J. (2011). Blurred borders: transnational migration between the Hispanic Caribbean and the United States. Chapel Hill: The University of North Carolina Press.

Duany, J. (2004). Between the nation and the diaspora: migration to and from Puerto Rico. In M. Toro-Morn \& M. Alicea (Eds.), Migration and Immigration: A Global View (pp. 177-196). Westport: Greenwood Press.

Duany, J. (2002). The Puerto Rican nation on the move: identities on the island and in the United States. Chapel Hill: The University of North Carolina Press.

FCB. (2019). Financial oversight and management board for Puerto Rico. Fiscal Control Board. Accessed on 09/29/2019. https://oversightboard.pr.gov/

Fox, B. (2018). Many in Puerto Rico still under tarps as storm threat looms. AP News, June, 20, 2018.

Glick, J. E. (2010). Connecting complex processes: a decade of research on immigrant families. Journal of Marriage and the Family, 72(3), 498-515.

Guo, G., \& Mullan Harris, K. (2000). The mechanisms mediating the effects of poverty on children's intellectual development. Demography, 37(4), 431-447.

Haskins, R., \& Sawhill, I. (2007). Introducing the issue. The Future of Children, 17(2), 3-16.

Hinojosa, J., Román, N., \& Meléndez, E. (2018). Puerto Rican post-Maria relocation by states. Center for Puerto Rican Studies, Hunter College, Centro, RB2018-RB2003.

Holpuch, A., \& Kilani, H. (2019). Hurricane Maria's lasting impact on Puerto Rico's children revealed in report. The Guardian, 26, 2019.

Hugo López, M. \& Velasco, G. (2011). A demographic portrait of Puerto Ricans: 2009. Pew Research Center, Statistical Profile. Accessed on 07/18/2017. http://www.pewhispanic.org/2011/06/13/a-demographicportrait-of-puerto-ricans/.

Landale, N., \& Hauan, S. M. (1996). Migration and premarital childbearing among Puerto Rican women. Demography, 33(4), 429-442.

Landale, N. S., Thomas, J. A., \& Van Hook, J. (2011). The living arrangements of children of immigrants. The Future of Children, 21(1), 42-70.

Manuel Krogstad, J. (2016). Historic population losses continue across Puerto Rico. Pew Research Center, Fact Tank. Accessed on 07/18/2017. http://www.pewresearch.org/fact-tank/2016/03/24/historicpopulation-losses-continue-across-puerto-rico/

Mayol-García, Y.H. and Burd, C. (2018). A binational perspective of Puerto Rican-Origin children's living arrangements: a decade of change and migration in Puerto Rico and the United States, 2006 and 2015. U.S. Census Bureau, SEHSD Working paper presented at PAA 2018, Poster Presentation. . https://www. census.gov//content/dam/Census/library/working-papers/2018/demo/SEHSD-WP2018-08.pdf

Mayol-García, Y.H. and O'Hare, W.P. (2019). The demography of childhood. In Handbook of Population (pp. 209-232). Dudley L. Poston Jr. (ed.). Switzerland: Springer.

McLanahan, S. (2004). Diverging destinies: how children are faring under the second demographic transition. Demography, 41(4), 607-628.

McLeod, J. D., \& Nonnemaker, J. M. (2000). Poverty and child emotional and behavioral problems: racial/ ethnic differences in processes and effect. Journal of Health and Social Behavior, 41, 137-161.

Montalvo, A. \& Laughlin, L. (2017). An island in crisis? A statistical portrait of recent Puerto Rican migration and socioeconomic outcomes between 2005 and 2015. U.S. Census Bureau, SEHSD Working Paper 
presented at PAA 2018, Poster Presentation. . https://www.census.gov/library/working-papers/2017 /demo/SEHSD-WP2017-21.html

Mora, M. T., Dávila, A., \& Rodríguez, H. (2018). Migration, geographic destinations, and socioeconomic outcomes of Puerto Ricans during La Crisis Boricua: implications for island and stateside communities post-Maria. Centro Journal, 30(3), 208-229.

Orengo-Aguayo, R., Stewart, R. W., de Arellano, M. A., Suarez-Kindy, J. L., \& Young, J. (2019). Disaster exposure and mental health among Puerto Rican youths after Hurricane Maria. JAMA Network Open, 2(4), e192619. https://doi.org/10.1001/jamanetworkopen.2019.2619.

Oropesa, R. S., \& Landale, N. S. (2000). From austerity to prosperity? Migration and child poverty among mainland and island Puerto Ricans. Demography, 37(3), 323-338.

Santos-Lozada, A.R. (2017). Puerto Rican diaspora in the aftermath of hurricane María. Accessed on 09/29/ 2019. http://sites.psu.edu/prdiasporastudy

Semega, J.L., Fontenot, K.R. \& Kollar, M.A. (2017). Income and poverty in the United States: 2016. U.S. Census Bureau, Current Population Reports P60-259. Accessed on 8/13/2018. Available at https://www. census.gov/content/dam/Census/library/publications/2017/demo/P60-259.pdf

Sutter, J.D. \& Hernandez, S. (2018). 'Exodus' from Puerto Rico: a visual guide. CNN Investigates, February 21, 2018. Accessed on 06/30/2019. https://www.cnn.com/2018/02/21/us/puerto-rico-migration-datainvs/index.html

The George Washington University. (2018). Ascertainment of the estimated excess mortality from Hurricane María in Puerto Rico. Available at: https://prstudy.publichealth.gwu.edu/

Turney, K., \& Goodsell, R. (2018). Parental incarceration and children's wellbeing. The Future of Children, 28(1), 147-164.

U.S. Census Bureau. (2018). American community survey (ACS): impacts of hurricanes on data collection and estimate quality for Puerto Rico, Texas, and Florida. U.S. Census Bureau. Accessed on 09/28/2019. https://www.census.gov/programs-surveys/acs/technical-documentation/user-notes/2018-02.html

U.S. Census Bureau. (2019). American community survey (ACS): about the American Community Survey. U.S. Census Bureau. Accessed on 09/28/2019. https://www.census.gov/programs-surveys/acs/about.html

Publisher's note Springer Nature remains neutral with regard to jurisdictional claims in published maps and institutional affiliations. 